\title{
DIURNAL RHYTHMS IN SEMEN YIELDS AND MATING BEHAVIOUR IN THE DOMESTIC COCK
}

\author{
By P. E. LAKE and D. G. M. WOOD-GUSH \\ Agricultural Research Council Poultry Research Centre, West Mains Road, Edinburgh
}

$\mathrm{W}$ ELLS $^{1}$ has suggested that much avian behaviour may be based on inherent rhythms. The mating activity of the domestic cock shows a marked diurnal rhythm ${ }^{2-4}$, in that the majority of matings occur in the late afternoon. Riley ${ }^{5}$ and Macartney ${ }^{6}$ found that mitotic activity in the cock's testis was greatest during the night, thus suggesting that the production of spermatozoa may not be uniform during the day. The object of this work is to investigate the relationship between semen yields and mating activity in the Brown Leghorn cock.

Twelve cocks selected on their ability to produce adequate semen samples were used as semen donors. They were kept in individual cages where they had access to mash and water at all times, and in the late afternoon they were given grain. They were divided into three groups of four, and semen was collected on three days--May 30, June 4 and June 9 -during the periods 08.30-09.30, 12.00-13.00 and 17.00-18.00 hr. Each group was tested at a different time on subsequent days of collection. This procedure was followed as it was considered, from previous experience, that over the short period of the experiment there would be no systematic changes in semen yields. Semen was collected by lumbar massage three times during the hours stipulated above, and the total volume and total absolute number of spermatozoa yielded were assessed for each cock.

To estimate the number of spermatozoa, a Spekker photo-electric fluorimeter was used as a turbidimeter, with a 1 in 500 dilution of semen and neutral filters (H508). The instrument had been calibrated previously against counts of spermatozoa made with a haemocytometer. The diluting fluid was a 1.025 per cent solution of sodium chloride containing 1 per cent formalin.

Two cocks of the same age and breed as the donors were used for observations on mating frequencies. They were each resident in a pen with laying hens and were each observed on two days between May 30 and June 10 during the hours of semen collection. In their pens they had free access to mash and water and were given grain at the same time as the donors.

The volumes of the semen yields for each cock are shown in Table 1. A two-way analysis of variance

Table 1. Voldme of Semen YleLdos (MEasured IN MA.) COLLECTED Table 1. VOLUME OF SEMEN Y YELOS (MEA
FROM EACH COCK

\begin{tabular}{|c|c|c|c|}
\hline \multirow{2}{*}{ Cocks } & \multicolumn{3}{|c|}{ Times of eollection } \\
\hline & $0830-09.30$ & $12.00-13.00$ & $17.00-18.00$ \\
\hline $\begin{array}{r}1 \\
2 \\
3 \\
4 \\
5 \\
6 \\
7 \\
8 \\
9 \\
10 \\
11 \\
12\end{array}$ & $\begin{array}{l}0 \cdot 82 \\
0 \cdot 20 \\
0 \cdot 48 \\
0 \cdot 36 \\
0 \cdot 62 \\
0 \cdot 14 \\
0 \cdot 50 \\
0.58 \\
0.28 \\
0.63 \\
0.18 \\
\text { NiI }\end{array}$ & $\begin{array}{l}0 \cdot 48 \\
0 \cdot 16 \\
0 \cdot 40 \\
0 \cdot 30 \\
0 \cdot 63 \\
0 \cdot 12 \\
0 \cdot 01 \\
0 \cdot 48 \\
0 \cdot 30 \\
0 \cdot 77 \\
0 \cdot 22 \\
0 \cdot 40\end{array}$ & $\begin{array}{l}0.86 \\
0.47 \\
0.70 \\
0.72 \\
0.71 \\
0.19 \\
0.52 \\
0.46 \\
0.33 \\
0.90 \\
0.51 \\
0.29\end{array}$ \\
\hline
\end{tabular}

Table 2. TOTAL ABSOLUTE NUMBFR OF SPERMATOZOA YIELDED BY

\begin{tabular}{|c|c|c|c|}
\hline \multirow{2}{*}{ Cocks } & \multicolumn{3}{|c|}{ Times of collection } \\
\hline & $08.30-09.30$ & $12.00-13.00$ & $17.00-18.00$ \\
\hline $\begin{array}{r}1 \\
2 \\
3 \\
4 \\
5 \\
6 \\
7 \\
8 \\
9 \\
10 \\
11 \\
12\end{array}$ & $\begin{array}{c}6 \cdot 333 \times 10^{\circ} \\
1 \cdot 278- \\
3 \cdot 487 \\
2 \cdot 991 \\
3 \cdot 014 \\
0 \cdot 804 \\
3 \cdot 208 \\
3 \cdot 277 \\
1 \cdot 657 \\
5 \cdot 068 \\
1 \cdot 000 \\
\text { Nil }\end{array}$ & $\begin{array}{l}3 \cdot 302 \times 10^{\circ} \\
1 \cdot 16 \\
3 \cdot 478 \\
2 \cdot 841 \\
3 \cdot 255 \\
0 \cdot 503 \\
\text { Nil } \\
2 \cdot 674 \\
1 \cdot 675 \\
5 \cdot 876 \\
0.900 \\
2 \cdot 390\end{array}$ & $\begin{array}{l}5 \cdot 798 \times 10^{2} \\
2 \cdot 156 \\
4 \cdot 473 \\
6 \cdot 724 \\
3 \cdot 428 \\
0 \cdot 938 \\
2 \cdot 637 \\
2 \cdot 739 \\
1 \cdot 705 \\
7 \cdot 388 \\
2 \cdot 385 \\
1 \cdot 538\end{array}$ \\
\hline
\end{tabular}

on these data showed that the differences between cocks were significant $(P<0.01)$ and that the differences between yields at the various times of collection were also significant $(P<0.01)$. The greatest yields were found to occur in the late afternoon.

The total absolute number of spermatozoa yielded by these cocks was also found to vary significantly between cocks $(P<0.01)$ and between times of collection $(P<0.05)$ when the data were analysed by means of a two-way analysis of variance. As with volume, the absolute number of spermatozoa was found to be greatest in the late afternoon (Table 2).

Nineteen matings were performed by the control cocks during the hours of observation, and of these thirteen occurred between 17.00-18.00 hours, thus showing that mating activity is high when semen yields are at their best. These results differ from those reported by Parker, McKenzie and Kempsters. These workers used a semen collector attached to the cloaca of the cock, which intercepted emissions from cloaca during natural matings and in the periods between matings. They reported that semen volume was greatest in the morning and that the total number of spermatozoa yielded did not differ significantly between morning and afternoon. Attempts to use a semen collector of this type on the cocks at this laboratory have been repeatedly unsuccessful due to contamination with urine and fluids from the cloacal glands, and in this study only direct reflex emissions from the ejaculatory ducts were taken to represent fowl semen, so as to avoid contamination with cloacal fluids and urine. This difference in technique may explain the variance between these results and those of Parker et al. (loc. cit.).

The relationship between semen yields and mating activity is under further investigation and will be reported elsewhere.

${ }^{1}$ Wells, G. P., "The Sources of Animal Behaviour" (H. K. Lewis and Co., Ltd., London, 1955).

${ }^{2}$ Upp, C. W., Poult. Sci., r, 225 (1928).

3 Parker, J. E., McKenzie, F. F., and Kempster, H. L., Poult. Sci. 19, $19 \mathrm{i}(1940)$.

4 Long, E., and Godfrey, G. F., Poult. Sci., 31, 665 (1952).

5 Riley, G. M., Poult. Sci., 19, 360 (1940).

'Macartney, E. L., Poult. Sci., 21, 130 (1942). 